\title{
Modelagem da retenção de herbicidas em zonas ripárias
}

\author{
Alexandra P. de Pinho', Antônio T. de Matos ${ }^{2}$, Liovando M. da Costa ${ }^{3}$, Lawrence A. Morris ${ }^{4}$ \& Mauro A. Martinez ${ }^{2}$
}

\begin{abstract}
RESUMO
O presente trabalho teve como objetivo investigar a retenção de atrazina e picloram, transportados via escoamento superficial, em zona ripária. Para isto, simulou-se um escoamento superficial, contendo uma mistura de caulinita, atrazina e picloram, dentro de zonas ripárias estabelecidas ao longo de plantações de pinheiros do Nordeste do Estado da Geórgia, EUA. Cinco parcelas foram instaladas dentro de zonas ripárias, apresentando declividades diferentes (2, 5, 10, 15 e 20\%). Os efeitos da umidade do solo e da presença do horizonte $\mathrm{O}$ na retenção dos dois herbicidas foram avaliados. Um modelo exponencial, comumente utilizado na estimativa de redução da DBO e de nutrientes em tratamento por escoamento superficial, foi empregado na estimativa de redução de herbicidas e caulinita em zonas ripárias. O modelo possibilitou estimar com razoável precisão, a remoção de caulinita e atrazina da mistura em escoamento ao longo de zonas ripárias de $10 \mathrm{~m}$ de comprimento. Em geral, a declividade foi o parâmetro que apresentou melhor correlação com a retenção dos contaminantes presentes na mistura em escoamento na zona ripária. O horizonte $\mathrm{O}$, mais espesso nas maiores declividades, favoreceu tanto a sedimentação da caulinita como a adsorção da atrazina.
\end{abstract}

Palavras-chave: escoamento superficial, mata ciliar, atrazina, picloram, horizonte $\mathrm{O}$

\section{Modeling of herbicide retention in riparian zones}

\begin{abstract}
This work aimed to investigate the retention of atrazine and picloram, carried by surface flow, in riparian zones. The surface flow, containing a mixture of both herbicides and kaolin, was then simulated within riparian zones established in pine plantations in north-eastern Georgia, USA. Five plots were established within riparian zones, each with a different slope $(2,5,10$, 15 and 20\%). The influence of the initial moisture and of the $\mathrm{O}$ horizon condition in herbicide retention was analyzed. An exponential model, commonly used for the estimate of biochemical demand of oxygen (BOD) and nutrients attenuation in overland flow treatment, was used to estimate the attenuation of kaolin and herbicides in riparian zones. The model allowed an accurate estimate of the attenuation of kaolin and atrazine from the surface runoff mixture along $10 \mathrm{~m}$ of riparian zone. Generally, slope showed the best correlation with retention of the pollutants presented in the runoff mixture within the riparian zone. The $\mathrm{O}$ horizon present in the steeper slopes improved the sedimentation of kaolin and the atrazine adsorption.
\end{abstract}

Key words: surface runoff, streamside vegetation, atrazine, picloram, O horizon

${ }^{1}$ Centro de Pesquisa Nacional de Gado de Corte - EMBRAPA, BR 262 km 4, Caixa Postal 154, CEP 79002-970. Campo Grande, MS. Fone: (67) $3368-2028$. E-mail: alexandra@cnpgc.embrapa.br

${ }^{2}$ DEA/UFV. Rua P.H. Rolfs s/n, CEP 36571-000, Viçosa, MG. Fone: (31) 3899-1054. E-mail: atmatos@ufv.br

${ }^{3}$ DPS/UFV. Fone: (31) 3899-1886. E-mail: liovandomc@yahoo.com.br

${ }^{4}$ Daniel B. Warnell School of Forestry Resources, University of Georgia, Athens, Georgia, EUA, ZIP: 30602. Fone: (706) 542-2532. E-mail: Imorris@arches.uga.edu 


\section{INTRODUÇÃO}

Uma das práticas mais eficientes no controle da poluição não-pontual é o estabelecimento de faixas com cobertura vegetal, geralmente gramíneas, para impedirem que poluentes, por meio do escoamento superficial, entrem em contato com águas superficiais. A agricultura intensiva é uma forte geradora de poluição não-pontual e, entre os poluentes mais comuns estão os sedimentos, os fertilizantes e os pesticidas.

$\mathrm{Na}$ silvicultura comercial, os herbicidas atrazina e picloram são muito utilizados trazendo riscos de contaminação para o solo e água. A atrazina, herbicida do grupo das triazinas, é utilizada no controle de plantas invasoras de folhas largas e gramíneas. Embora com tendência de se ligar às partículas de solo, a contaminação do lençol freático com este herbicida é freqüente (Paterson \& Schoonor, 1992). O picloram, herbicida sistêmico, é utilizado no controle de plantas invasoras lenhosas e de um grande espectro de plantas invasoras de folhas largas e utilizado intensivamente em sistemas florestais. $\mathrm{O}$ picloram é pouco adsorvido pelas partículas de solo e, conseqüentemente, pode ser transportado na superfície do solo, via escoamento superficial.

Inúmeros estudos indicam intensa contaminação de águas superficiais por herbicidas (Cheng, 1990) pela qual, a partir da década de 70 , várias medidas foram determinadas em todo o mundo visando a redução da poluição dos recursos hídricos por fontes não-pontuais. A Comissão Florestal dos Estados Unidos exige que áreas de atividade silvicultural mantenham as zonas ripárias intactas ao longo dos cursos d'água.

Apesar de a atrazina ser um herbicida bastante estudado, há poucas informações disponíveis sobre sua retenção em zonas ripárias (Mersie et al., 1999).

No tratamento via escoamento superficial, a água residuária é aplicada na parte mais elevada de uma área coberta com gramíneas (EPA, 1981). Com o uso deste método, têm-se obtidos taxas de remoção de 75 a $90 \%$ do nitrogênio, 50 a $70 \%$ do fósforo e de até $90 \%$ dos sólidos em suspensão (Loures, 2002).

Os mecanismos responsáveis pela remoção de nitrogênio, via escoamento superficial, incluem sua absorção pelas plantas, oxidação biológica e volatilização da amônia. A remoção de fósforo ocorre via adsorção pelas argilas coloidais e precipitação. Sólidos coloidais e em suspensão são removidos principalmente via sedimentação, filtração através da vegetação e da camada de liteira, aqui denominada horizonte 0 , e adsorção pela camada de filmes biológicos (Barfield et al., 1979). Uma vez que alguns herbicidas, como a atrazina, se encontram ligados às partículas sólidas e aos sedimentos, a sua remoção em faixas vegetadas ocorre por meio dos mesmos mecanismos que atuam na remoção de sólidos em suspensão.

A retenção de sedimentos e nutrientes que entram nas zonas ripárias via escoamento superficial, foi previamente estudada e modelada (Hayes et al., 1979; McCutcheon et al., 2000; Lowrance et al., 2001). Existem modelos que descrevem a retenção de sedimentos (Barfield et al., 1979) e de herbicidas (Mersie et al., 1999) em faixas de proteção com gramíneas. Geralmente, esses modelos têm, como principais parâme- tros, a distância percorrida pelo líquido em escoamento, a declividade da faixa, o grau de convergência das linhas de corrente da mistura e a densidade de cobertura sobre o solo. Apesar de complexos, esses modelos não contemplam outros parâmetros de importância, como características de horizonte $\mathrm{O}$.

Durante o escoamento sobre a superfície do solo o líquido entra em contato com a camada da superfície que contém, além de minerais, matéria orgânica em degradação e serrapilheira. Acredita-se que haja uma alta correlação entre o tempo de contato do líquido em escoamento com o solo e a eficiência de remoção de poluentes em solução ou suspensão; entretanto, não foram encontradas, na literatura consultada, referências a modelos que proporcionem a estimativa da remoção de herbicidas a partir de dados de tempo de detenção, determinado com base em propriedades físicas e características operacionais do líquido na zona ripária.

De acordo com Smith \& Schroeder (1985) a redução da concentração de matéria orgânica presente em águas residuárias, quando em escoamento sobre o solo, pode ser estimada em função do comprimento da faixa e da taxa de aplicação. Este modelo foi utilizado por Loures (2002) para avaliar a eficiência do método de tratamento de esgoto doméstico por escoamento superficial na redução de poluentes (nitrogênio, fósforo, cálcio e DBO).

O estudo de modelos que possibilitam a estimativa da capacidade de retenção e depuração de poluentes é importante, pois, o seu emprego permite predizer os riscos de contaminação dos sistemas aquáticos em decorrência do emprego de pesticidas em áreas exploradas com agricultura podendo, também, ser usado em planos de controle de poluição nas mesmas áreas. No Brasil não existe um modelo especificamente desenvolvido para estimativa da capacidade que zonas ripárias exercem na atenuação de poluição em áreas agrícolas.

Este trabalho teve como objetivo o ajuste de um modelo matemático para estimativa da retenção de herbicidas ao longo de zonas ripárias, em diferentes condições de declividade e umidade do solo, com a presença ou não do horizonte $\mathrm{O}$.

\section{MATERIAL E MÉTODOS}

Os ensaios de escoamento superficial foram conduzidos em parcelas experimentais implantadas em zonas ripárias estabelecidas em plantação de pinheiros (Pinus taeda), na Bacia Hidrográfica do Rio Oconee, Condados de Clarke, Putnam e Jasper, localizados no nordeste do Estado da Geórgia, EUA.

A declividade das áreas onde as parcelas foram implantadas, variou de 2 a $20 \%$, enquanto a vegetação constituinte da zona ripária era, em todas as parcelas, exceto naquelas localizadas em áreas com declividade de aproximadamente $2 \%$, dominada por carvalhos (Liquidambar styracifua, Quercus rubra, Quercus falcata, Carya tomentosa). A superfície do solo encontrava-se coberta de folhas, as quais formavam uma espessura de 0,25 a $19 \mathrm{~cm}$, com valor médio de $5 \mathrm{~cm}$; além dessas parcelas, estabeleceram-se parcelas adicionais nas áreas experimentais com declividade intermediária $(5,10$ e 
$15 \%$ ) nas quais o horizonte $\mathrm{O}$ foi removido a fim de se avaliar a influência dessa camada na retenção dos herbicidas.

A mistura utilizada para promover o escoamento superficial foi aplicada em uma taxa equivalente à proporcionada por um evento de alta intensidade $\left(50 \mathrm{~mm} \mathrm{~h}^{-1}\right)$ de precipitação, determinado em um período de retorno de um ano, imediatamente após a aplicação dos herbicidas. $\mathrm{O}$ volume de líquido em escoamento superficial $( \pm 13.000 \mathrm{~L})$ foi estimado tomandose por base uma área de $1.600 \mathrm{~m}^{2}$ (0,16 ha), utilizando-se o Método de Número de Curva, do Serviço de Conservação de Solos dos EUA (US Soil Conservation Service, 1986).

As concentrações de atrazina e picloram na mistura foram de 55 e $35 \mu \mathrm{g} \mathrm{L}^{-1}$, respectivamente, enquanto que a de caulinita foi de $5 \mathrm{~g} \mathrm{~L}^{-1}$. A caulinita foi incluída na mistura como colóides individuais $(<20 \mu \mathrm{m})$ e pequenos agregados. Três tanques de $1.140 \mathrm{~L}$ foram utilizados para preparar a mistura e manter a concentração uniforme durante a aplicação do líquido a ser escoado superficialmente.

Para distribuição da mistura na parte alta das faixas de escoamento ( $5 \mathrm{~m}$ de largura por $10 \mathrm{~m}$ de comprimento) instalou-se um sistema distribuidor com $5 \mathrm{~m}$ de largura, semelhante ao descrito por McCutcheon et al. (2000) (Figura 1).

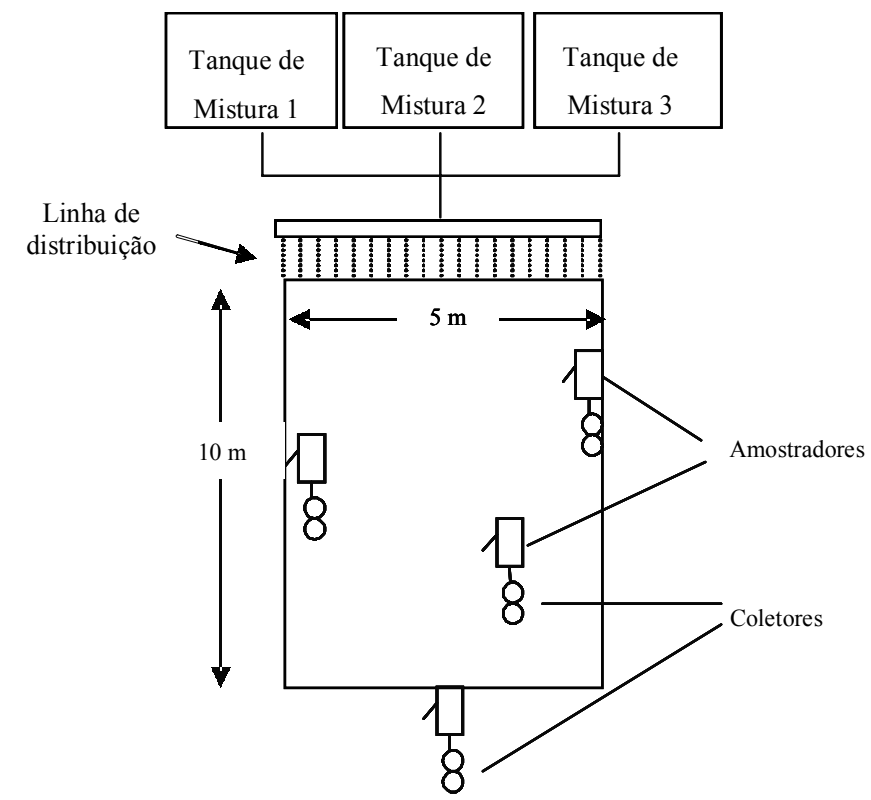

Figura 1. Esquema da área experimental e dos sistemas de distribuição e coleta da mistura em escoamento superficial

As aplicações ocorreram durante o verão, quando a vegetação se encontrava em crescimento ativo e a umidade do solo é baixa, e durante o inverno, quando a cobertura de vegetação é mínima e a umidade do solo se encontra próximo à capacidade de campo. O aparelho Time-domain reflectometry (TDR) foi utilizado para avaliar o conteúdo, movimento e armazenamento de água no solo abaixo das parcelas. Este método vem sendo largamente utilizado para tal finalidade, uma vez que cuida de medidas não destrutivas (Noborio, 2001).

Após $30 \mathrm{~min}$ do início das aplicações, media-se a velocidade do escoamento superficial com o auxílio de uma tinta que era aplicada à mistura; o tempo em que a mistura impreg- nada com tinta percorria $1 \mathrm{~m}$, correspondia à velocidade; essas medidas foram realizadas em toda a extensão das parcelas.

Coletores de escoamento superficial foram posicionados a 2, 4, 6 e $10 \mathrm{~m}$ no interior das parcelas (Figura 1). Amostras de $500 \mathrm{~mL}$ da mistura de escoamento superficial foram coletadas três vezes durante a aplicação (no início, metade e final da simulação), armazenadas em frascos de vidro e mantidas a $4{ }^{\circ} \mathrm{C}$, até o momento da análise.

\section{Análise dos herbicidas}

Realizou-se a determinação da concentração dos herbicidas por meio de teste de imunoadsorção com enzima ligada ao anticorpo (ELISA, Strategic Diagnostics Inc., Newark, Delaware), em faixa de detecção de 0,04 a 5,0 $\mu \mathrm{g} \mathrm{kg}^{-1}$ para a atrazina e 0,87 a $20 \mu \mathrm{g} \mathrm{kg}^{-1}$ para o picloram. As análises foram realizadas no Laboratório de Pesticidas e Resíduos Tóxicos da Universidade da Geórgia, EUA.

\section{Análise dos dados}

Com auxílio do programa estatístico Statistica (Statistica, 1999), o modelo exponencial foi ajustado aos valores das médias obtidas nas aplicações efetuadas nas estações seca e chuvosa em zonas ripárias com horizonte $\mathrm{O}$ intacto.

Para avaliação da dependência existente entre o coeficiente de decaimento $(\mathrm{K})$ dos contaminantes da mistura em escoamento superficial e a declividade, o percentual de água retida, a velocidade de escoamento e a umidade inicial do solo nas zonas ripárias, fez-se um estudo de correlação de Pearson, com o auxílio do programa estatístico SAS (SAS, 1999).

Para modelar a redução da concentração dos herbicidas ao longo das zonas ripárias utilizou-se o mesmo modelo apresentado por Loures (2002), em que:

$$
\frac{\mathrm{C}_{\mathrm{s}}}{\mathrm{C}_{0}}=\mathrm{A} \mathrm{e}^{(-\mathrm{KZ})}
$$

sendo:

Cs - a concentração do contaminante a uma distância x do ponto de aplicação na parte mais elevada da faixa de escoamento, $\mathrm{mg} \mathrm{L}^{-1}$

$\mathrm{C}_{0}$ - a concentração do contaminante na parte mais elevada da faixa de escoamento, $\mathrm{mg} \mathrm{L}^{-1}$

A - o parâmetro de ajuste da equação

$\mathrm{K}$ - o coeficiente de decaimento do contaminante na faixa de escoamento

$\mathrm{Z}$ - a distância ao longo da faixa, $\mathrm{m}$

\section{RESULTADOS E DISCUSSÃO}

Na Figura 2 tem-se as curvas experimentais e as respectivas equações exponenciais ajustadas, calculadas com a média da concentração relativa de caulinita, atrazina e picloram, em função da distância percorrida pela mistura em escoamento, nas parcelas onde o horizonte $\mathrm{O}$ foi mantido intacto. De 
caulinita $\square$ atrazina $\boldsymbol{\Delta}$ picloram

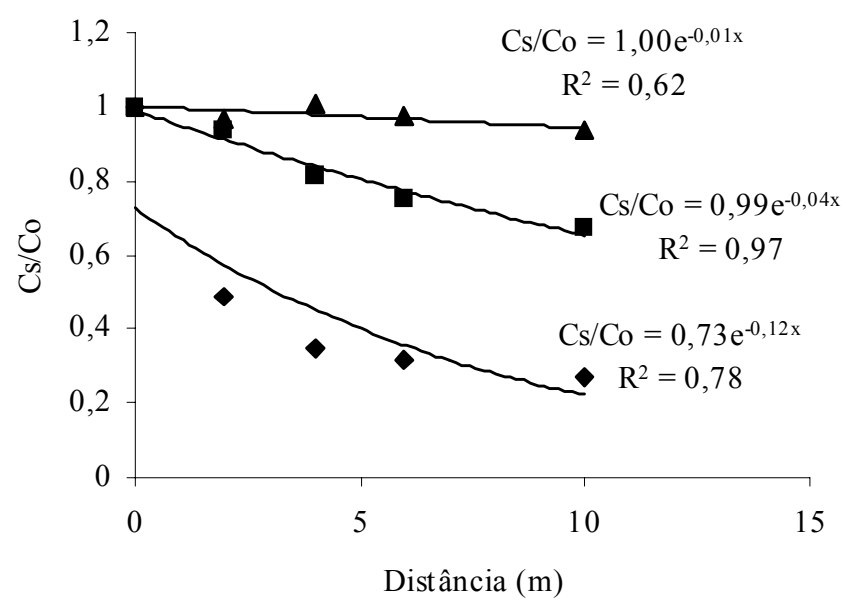

Figura 2. Concentração relativa de atrazina, picloram e caulinita ao longo das parcelas de 10 m de comprimento, cobertura com horizonte $\mathrm{O}$ (dados médios de todas as declividades)

modo geral, o modelo proporcionou melhor ajuste para os dados obtidos para a atrazina, enquanto o pior ajuste foi para os dados do picloram, indicando que este modelo pode predizer com mais confiabilidade os riscos de contaminação dos sistemas aquáticos pela atrazina.

Tendo em vista que o maior valor de $\mathrm{K}$ é indicativo de maior remoção do contaminante da mistura, a caulinita foi removida com maior eficiência na zona ripária. O picloram, por ser um herbicida com fraca adsorção à matriz do solo e à matéria orgânica, apresentou baixo valor de K, o que demonstrou pequena interação com o meio, ao longo da zona ripária. Este resultado indica que a modelagem do transporte de picloram em escoamento superficial não é eficiente na prevenção da contaminação dos sistemas aquáticos.

$\mathrm{Na}$ Tabela 1 estão apresentados os resultados das análises de correlação entre declividade da área, água retida, velocidade de escoamento e umidade do solo e o coeficiente de decaimento do contaminante nas faixas.

A sedimentação dos maiores agregados de caulinita (Tabela 1) foi afetada, principalmente, pela velocidade da mistura em escoamento superficial, tendo o coeficiente K apresentado forte correlação negativa com esta variável.

Ressalta-se, que na análise em que todas as parcelas são consideradas, a declividade não foi o único parâmetro responsável pela predição da velocidade do escoamento superficial, pois parcelas com a mesma declividade apresentaram velocidades diferentes quando o horizonte $\mathrm{O}$ foi removido ou mantido intacto. A análise das correlações referentes aos dados obtidos nas parcelas experimentais onde o horizonte O foi mantido intacto indica que a declividade da área passou a apresentar boa correlação com o coeficiente K, substituindo a velocidade de escoamento como única variável significativamente correlacionada com este coeficiente. Acredita-se que tal correlação não foi melhor em razão das diferenças existentes entre as parcelas experimentais, considerando-se a profundidade do horizonte $\mathrm{O}$.

No caso da atrazina, o coeficiente $\mathrm{K}$ foi significativamente correlacionado com a declividade, tanto nas análises dos dados globais do experimento, quanto nos dados obtidos nas parcelas em que o horizonte $\mathrm{O}$ foi mantido intacto. A água retida, a velocidade de escoamento e as condições de umidade, não apresentaram correlação com o coeficiente K.

No caso do picloram, nenhum dos parâmetros associados às parcelas apresentou boa correlação com o coeficiente K, uma vez que este herbicida é caracteristicamente solúvel na água e pouco adsorvido às partículas presentes no escoamento superficial. Este resultado indica que o modelo precisa ser ajustado quando compostos com alta solubilidade em água e baixa adsorção às partículas em suspensão forem considerados.

Para os três contaminantes, o coeficiente K aumentou com a declividade da área, mas esta correlação foi significativa ( $\mathrm{p}$ d" 0,01$)$ apenas para caulinita e atrazina. As curvas e as equações ajustadas para a correlação entre a declividade e os três contaminantes estão apresentadas na Figura 3.

A correlação entre a velocidade do escoamento e o coeficiente $\mathrm{K}$ somente foi significativo $(\mathrm{p}<0,01)$ para caulinita, sendo que o coeficiente aumenta sempre que a velocidade
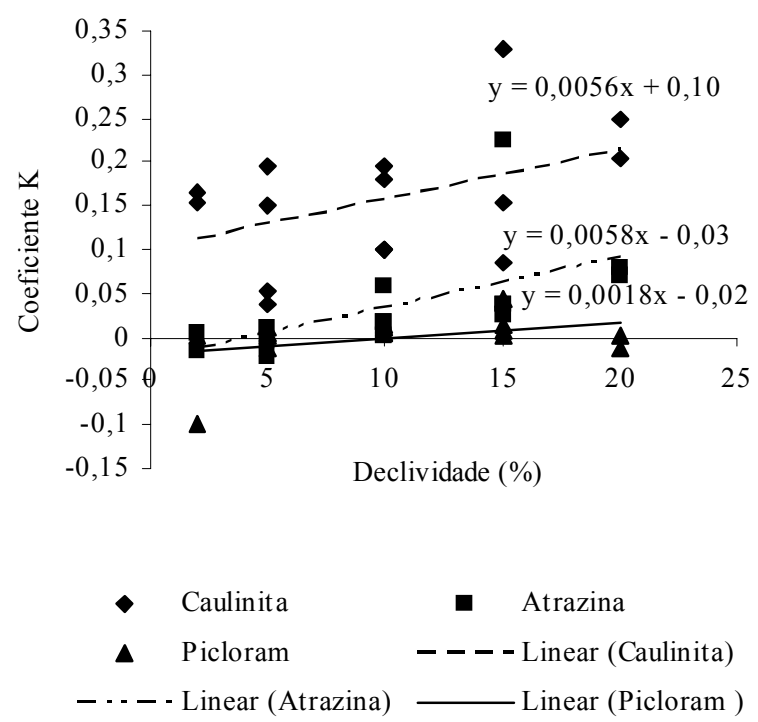

Figura 3. Correlação entre a declividade das parcelas e o coeficiente K obtido para a caulinita, atrazina e picloram para os dados globais do experimento (parcelas com e sem o horizonte O)

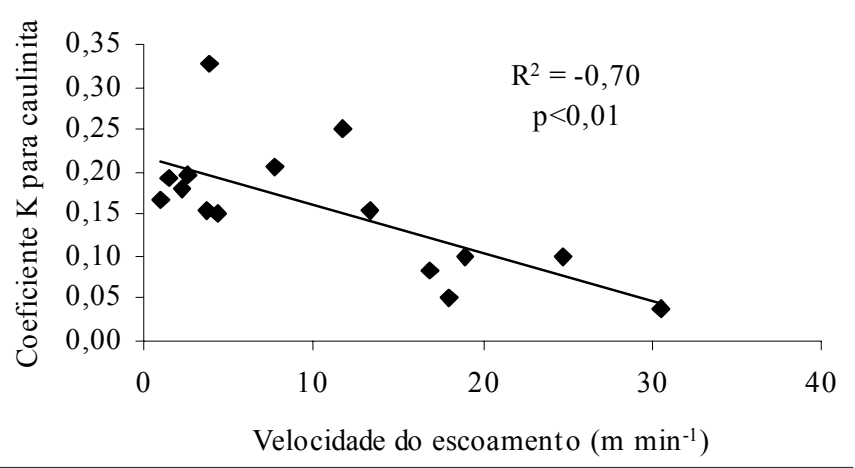

Figura 4. Correlação entre a velocidade de escoamento ao longo da parcela e o coeficiente $\mathrm{K}$ obtido para a caulinita, para os dados globais do experimento (parcelas com e sem o horizonte $\mathrm{O}$ ) 
Tabela 1. Correlações entre o coeficiente $\mathrm{K}$ obtido para caulinita, atrazina e picloram e a declividade, água retida, velocidade de escoamento e umidade inicial do solo

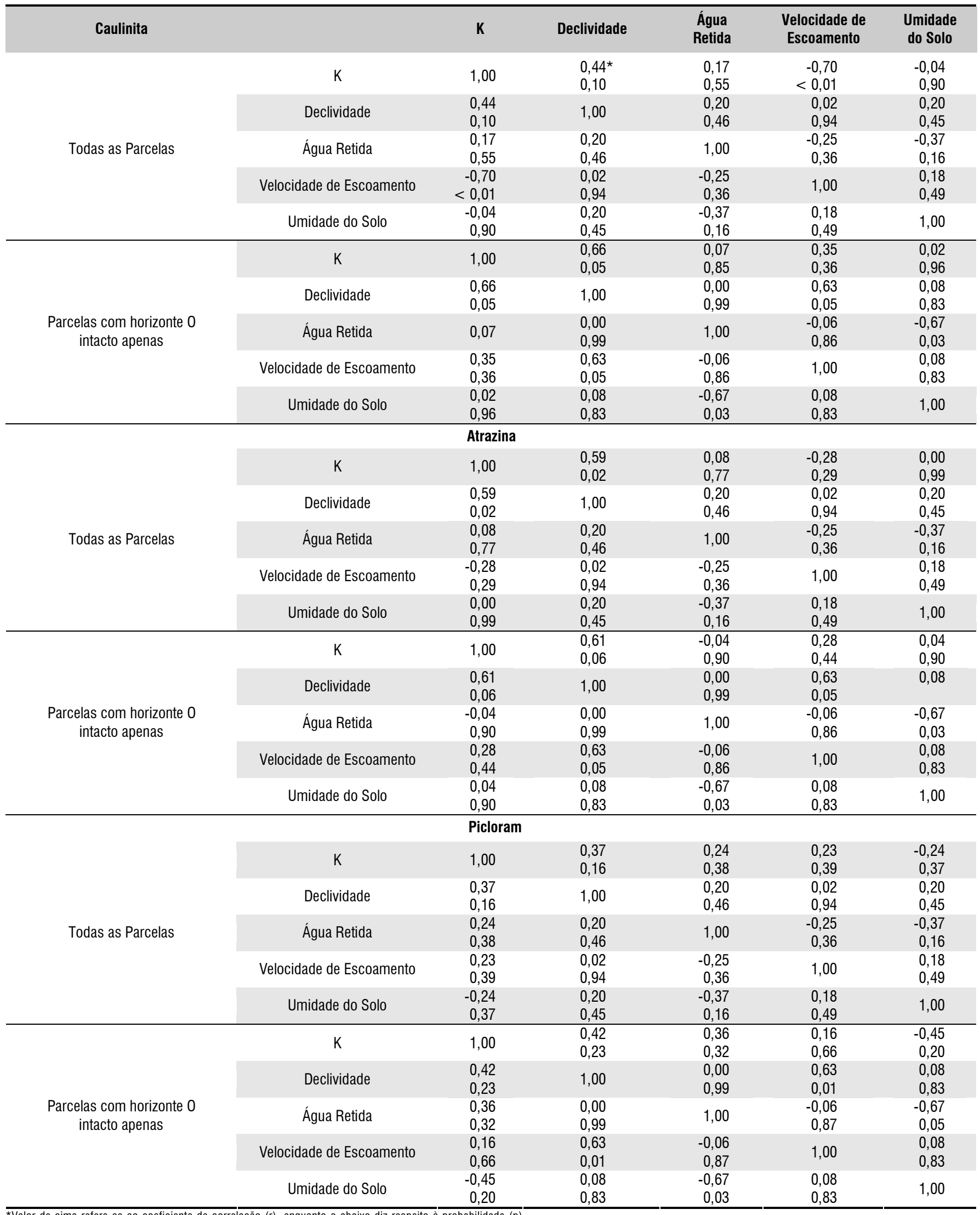

*Valor de cima refere-se ao coeficiente de correlação $(\mathrm{r})$, enquanto 0 abaixo diz respeito à probabilidade $(\mathrm{p})$ 
de escoamento da mistura diminui. Este resultado era esperado, uma vez que este contaminante, entre os três estudados, é o único com capacidade de sedimentação, que está intimamente associada à velocidade e consequentemente ao tempo de sedimentação.

Muito tem sido debatido a respeito da eficiência de zonas ripárias no sentido de evitar que poluentes presentes em escoamento superficial atinjam águas superficiais (Lowrance et al., 1997; Oliveira, 1999; Castelle \& Johnson, 2000; Vellidis et al., 2002). Os resultados indicam que mesmo zonas ripárias estreitas podem ser efetivas na redução das concentrações de argilas e herbicidas com características de adsorção moderadas, desde que a zona ripária seja formada por florestas manejadas com árvores adultas e o horizonte $\mathrm{O}$ bem desenvolvido.

Os resultados obtidos neste trabalho indicam que o horizonte $\mathrm{O}$ proporcionou superfície para adsorção e reduziu significativamente a velocidade de escoamento, aumentando, portanto, o tempo de detenção do líquido na zona ripária e, consequentemente, a oportunidade para sedimentação das partículas. Possivelmente, por ser bem desenvolvido, o horizonte A, existente abaixo do horizonte $\mathrm{O}$, apresenta elevados conteúdos de matéria orgânica, possibilitando maior retenção de poluentes. A sua alta macroporosidade também proporcionou maior infiltração de água e, conseqüentemente, menor velocidade de escoamento superficial. Os resultados obtidos contrastam, porém, com estudos anteriores, que determinaram pequena retenção de contaminantes contidos em soluções em escoamento em faixas de alta declividade, cobertas com gramíneas (Dillaha et al., 1989).

Apesar da variabilidade inerente ao processo, acredita-se que o uso de um modelo simples, como o empregado, possa ser utilizado na predição da retenção de contaminantes em zonas ripárias. Sua grande utilidade prática é a utilização na estimativa do decaimento de herbicidas e caulinita em outras áreas, possibilitando-se o dimensionamento das zonas ripárias, de acordo com as necessidades locais.

\section{CONCLUSÕES}

1. A concentração de caulinita foi a que mais decresceu enquanto a de picloram não foi significativamente reduzida ao longo da zona ripária.

2. A declividade foi o parâmetro que apresentou maior correlação com o coeficiente de decaimento do contaminante da mistura em escoamento superficial.

3. A manutenção do horizonte $\mathrm{O}$ em zonas ripárias mostrou-se fundamental para a remoção de contaminantes, tendo interferido tanto na sedimentação da caulinita como na adsorção da atrazina.

4. O modelo exponencial mostrou-se eficaz na predição da remoção de contaminantes (caulinita, atrazina e picloram) em escoamento superficial em zonas ripárias.

\section{AGRADECIMENTOS}

Os autores agradecem à CAPES, ao CNPq e à Environmen- tal Protection Agency/EUA, pelo financiamento da pesquisa. Adicionalmente, também agradecem ao Departamento de Engenharia Agrícola da Universidade Federal de Viçosa e ao Departamento de Recursos Florestais da Universidade da Geórgia, EUA, pela oportunidade de desenvolvimento do presente trabalho.

\section{LITERATURA CITADA}

Barfield, B.J.; Tollner, E.W.; Hayes, J.C. Filtration of sediment by simulated vegetation I. Steady-state flow with homogeneous sediment. Transactions of the ASAE, St. Joseph v.22, n.5, p.540-545, 1979.

Castelle, A.J.; Johnson, A.W. Riparian vegetation effectiveness. Technical Bulletin of the National Council for Air and Stream Improvement, Research Triangle Park, North Caroline, v.799, 26p, 2000.

Cheng, H.H. Pesticides in the soil environment: Processes, impacts, and modeling. Madison, Wiscosin: Soil Science Society of America Books Series, 1990. 530p.

Dillaha, T.A.; Renueau, S.M.; Lee, D. Vegetative filter strips for agricultural non point source pollution control. Transactions of the ASAE, St. Joseph, v.32, n.2, p.513-519, 1989.

EPA - Environmental Protection Agency. Land and treatment of Municipal wastewater. Cincinnati, Ohio: EPA, 1981. 483p.

Hayes, J.C.; Barfield, B.J.; Barnhisel, R.I. Filtration of sediment by simulated vegetation, II. Unsteady flow with non-homogeneous sediment. Transactions of the ASAE, St. Joseph, v.22, n.6, p.1063-1067, 1979.

Loures, A.P.S. Modelos de remoção de parâmetros qualitativos em sistema para tratamento de esgoto doméstico por escoamento superficial utilizando capim-coast-cross (Cynodon dactilon (L.) Pers). Viçosa: DEA/UFV, 2002. 114p. Dissertação Mestrado

Lowrance, R.; Vellidis, G.; Wauchope, R.D.; Gay, P.; Bosh, D.D. Herbicide transport in a managed riparian forest buffer system. Transactions of the ASAE, St. Joseph, v.40, n.4, p.10471057, 1997.

Lowrance, R.; Williams, R.G.; Inamdar, S.P.; Bosh, D.D.; Sheridan, J.M. Evaluation of coastal plain conservation buffers using the riparian ecosystem mangement model. Journal of the American Water Resources Association, St. Joseph, v.37, n.6, p.1445-1455, 2001.

McCutcheon, S.C.; Hayes, J.C.; Williams, C.A.; Weisskopf, C.P.; Klaine, S.J. Evaluation of vegetative filter strips to control urban runoff into Charleston harbor and other coastal waters. EPA report v.I. Clemson: Clemson University, 2000, 248p.

Mersie, W.; Seybold, C.A.; McNamee, C.; Huang, J. Effectiveness of switchgrass filter strips in removing dissolved atrazine and metolachlor from runoff. Journal of Environmental Quality, Madison, v.28, n.3, p.816-821, 1999.

R. Bras. Eng. Agríc. Ambiental, v.10, n.4, p.896-902, 2006. 
Noborio, K. Measurement of soil and water content and eletrical conductivity by time domain reflectrometry: A review. Computers and Eletronics in Agriculture, Munique, v.31, n.3, p.213-237, 2001.

Oliveira, L.F.C. Modelo para transporte de solutos no solo e no escoamento superficial. Viçosa: DEA/UFV, 1999. 171p. Tese Doutorado

Paterson, K.G.; Schoonor, J.L. Fate of allachlor and atrazine in a riparian zone field site. Water Environmental Research, Madison, v.64, p.274-283, 1992.

SAS. SAS/STAT User's guide, Version 8. Cary, N.C.: SAS Institute, Inc. 1999.
Smith, R.G.; Schroeder, E.D. Field studies of the overland flow process for the treatment of raw and primary treated municipal wastewater. Journal of Water Pollution Control Federation, New York, v.57, n.8, p.785-794, 1985.

Statistica. StatSoft, Inc. Release 5.5 A. StatSoft, Inc., Tulsa, OK, 1999.

US Soil Conservation Service. Urban hydrology for small watersheds. Technical Release 55, second edition. Washington: US Soil Conservation Service, 1986, 164p.

Vellidis, G.; Lowrance, R.; Gay, P.; Wauchope, R.D. Herbicide transport in restored riparian forest buffer system. Transactions of the ASAE, St. Joseph, v.45, p.89-597, 2002. 